\title{
Investigation into the Effect of Extended Laundering on the KES-F Mechanical Properties of an Easy Care Treated Cotton Fabric
}

\author{
Liberato Venant Haule \\ College of Engineering and Technology, University of Dar es Salaam, Dar es Salaam, Tanzania \\ Email: liberato.haule@udsm.ac.tz, liberatohaule@yahoo.co.uk
}

Received 20 February 2016; accepted 7 May 2016; published 10 May 2016

Copyright (C) 2016 by author and Scientific Research Publishing Inc. This work is licensed under the Creative Commons Attribution International License (CC BY). http://creativecommons.org/licenses/by/4.0/

\section{(c) (i) Open Access}

\begin{abstract}
The effect of extended laundering on cotton fabric treated with Dimethylol dihydroxyethyleneurea (DMDHEU) easy care finish was investigated and the fabric characterised by crease recovery performance and the Kawabata Evaluation System for Fabrics (KES-F). The KES-F results indicated that the mechanical handle properties of the DMDHEU treated cotton fabrics were affected by both the levels of application of the DMDHEU easy care finishes and the stress relaxation of the fabrics in aqueous conditions.
\end{abstract}

\section{Keywords}

DMDHEU, Extended Laundering, KES-F, Cotton Fabrics, Easy Care

\section{Introduction}

Dimethylol dihydroxyethyleneurea (DMDHEU) is applied to cotton fabrics in order to impart easy care properties such as crease resistance/recovery and dimensional stability. However generally the crease recovery performance is improved at the expense of strength loss and increased shear and bending rigidity [1]-[7]. Some of the detrimental effects of the easy care finish on the mechanical properties of the cotton fabrics can be reduced by incorporating softeners in the easy care formulation [8] [9]. In order to overcome the disadvantages of the DMDHEU easy care finishes, extensive research has focused on the polycarboxylic acids based easy care finishes and improved strength recovery has been reported [10]-[20]. However, DMDHEU still dominates the textile finishing due to its outstanding durability and low cost which attracts more attention. 
Previous studies on the wash durability of the DMDHEU treated cotton fabrics as assessed by the crease recovery angle (CRA) performance and surface and bulk analysis indicated that the DMDHEU easy care finish applied to cotton garment is durable almost for the entire life of the garment [21]. An investigation on the wash durability of the DMDHEU on domestic laundering machines and wet cleaning conditions indicated that the easy care finish is less durable on domestic laundering machine than wet cleaning conditions due to the aggressiveness of the former. During the study, the hand (tactile) properties of the fabrics were only evaluated based on the coefficient of friction and geometrical roughness using the KES-F system. The surface friction of the investigated fabrics was found to be higher for the domestic laundering than wet cleaning conditions due to fibrillation tendency of the substrates in former. The effects of DMDHEU concentrations on the hand properties were not considered [22].

In current study, the effects of extended laundering of DMDHEU treated cotton fabric on the fabric's mechanical properties as determined by the Kawabata Evaluation System for Fabrics (KES-F) were investigated.

The KES-F system was developed in Japan by a group led by Professor S. Kawabata in 1968 and came into operation 10 years later [23]-[26]. Originally the system was developed for objective evaluation of fabric "handle", and was also commonly used for product/process development, process control and optimisation. The KES-F technique measures the fabric mechanical and surface properties, Table 1, at load levels typical of normal human handling and end-user applications and the objective measurements are correlated to subjective handle properties of the material. The acquired handle properties such as fullness, smoothness and stiffness can objectively be compared and adjusted for quality and performance control purposes. Fabric making up performance can be controlled by predicting problems such as seam pucker from the KES-F fabric "fingerprint" and fabric drape and other end-use characteristics can also be predicted from the objective measurements.

\begin{tabular}{|c|c|c|}
\hline Parameter & Symbol & Units \\
\hline \multicolumn{3}{|l|}{ Tensile } \\
\hline Tensile linearity & $\mathrm{LT}$ & - \\
\hline Tensile energy per unit area & WT & gf.cm $/ \mathrm{cm}^{2}$ \\
\hline Resilience & $\mathrm{RT}$ & $\%$ \\
\hline Extension at specific load & EMT & $\%$ \\
\hline \multicolumn{3}{|l|}{ Shear } \\
\hline Shear stiffness & G & gf/cm.deg \\
\hline Hysteresis at $0.5^{\circ}$ & $2 \mathrm{HG}$ & $\mathrm{gf} / \mathrm{cm}$ \\
\hline Hysteresis at $5^{\circ}$ & 2HG5 & $\mathrm{gf} / \mathrm{cm}$ \\
\hline \multicolumn{3}{|l|}{ Bending } \\
\hline Bending stiffness & B & gf. $\mathrm{cm}^{2} / \mathrm{cm}$ \\
\hline Hysteresis width & $2 \mathrm{HB}$ & gf.cm/cm \\
\hline \multicolumn{3}{|l|}{ Compressional } \\
\hline Compressional linearity & $\mathrm{LC}$ & - \\
\hline Energy of compression & WC & gf.cm $/ \mathrm{cm}^{2}$ \\
\hline Resilience & $\mathrm{RC}$ & $\%$ \\
\hline Compressibility & $\mathrm{C}$ & $\%$ \\
\hline \multicolumn{3}{|l|}{ Thickness and weight } \\
\hline Thickness under a force of $0.5 \mathrm{gf} / \mathrm{cm}^{2}$ & To & $\mathrm{mm}$ \\
\hline Weight & $\mathrm{W}$ & $\mathrm{mg} / \mathrm{cm}^{2}$ \\
\hline Thickness under a force of $50 \mathrm{gf} / \mathrm{cm}^{2}$ & $\mathrm{Tm}$ & $\mathrm{mm}$ \\
\hline \multicolumn{3}{|l|}{ Surface } \\
\hline Coefficient of friction & MIU & - \\
\hline Mean deviation of MIU & MMD & - \\
\hline Geometrical roughness & SMD & $\mu \mathrm{m}$ \\
\hline
\end{tabular}


Previous work suggested that the KES-F tests may be used for investigating the mechanical changes of fabrics during wet processing and it was reported that fabric laundering reduces stiffness and increase smoothness, softness and fullness of processed cotton fabrics [26]. The KES-F test was used to assess the effects of fabric raisings on comfort, hand and mechanical properties of artificial suede. The increased number of raisings caused the suede to have a soft and smooth surface and improved perception of luxuriousness [27]. The hand properties of woven and knitted fabrics were investigated using the KES-F and frictional analyser tests and the KES-F results indicate that there is a good correlation between friction and tactile properties for knitted fabrics but not for woven fabrics [28]. Furthermore the Kawabata system was applied on investigation on the effects of fabric movements in front-loading washers on hand properties. The study established a relationship between fabric movements and hand properties and the relationship could be used by the washing machine manufacturers on design of washing programmes of various types of garments [29]. The Kawabata system has also been tested and recommended for the paper industry for the determination of objective mechanical properties which can be used to translate the subjective handle properties such as softness/smoothness [30]. KES-F was used for investigating the performance of the $\mathrm{TiO}_{2}$ as an easy care finishes for cotton material [31].

In this paper the effects of extended laundering, with perborate and a non-perborate detergent, on the KES-F handle properties of the DMDHEU treated cotton fabrics was investigated.

\section{Methodology}

\subsection{Materials}

Scoured, bleached, 100\% plain woven cotton fabric, $152 \mathrm{~g} / \mathrm{m}^{2}$ was supplied by Phoenix Calico, UK. Fixapret CP New (dimethylol dihydroxyethyleneurea, DMDHEU) was supplied by Dystar, UK. Magnesium chloride was supplied by Fisher Scientific, UK. The ECE non-phosphate detergent, ECE phosphate detergent and Tetra Acetyl Ethylene Diamine (TAED, 92\% active) were purchased from the Society of Dyers and Colourists (SDC), Bradford, UK. Sodium Perborate Tetrahydrate (97\%) active was purchased from Aldrich Chemicals Ltd., UK.

\subsection{Treatment Conditions}

Aqueous solutions of DMDHEU, 60, 100 and 140 g/L, and magnesium chloride , 12 g/L, 20 g/L and 28 g/L, respectively, were padded onto the cotton fabric at $80 \%$ wet pick up. The magnesium chloride was included in the padding solution as a catalyst during curing. The padded fabrics were oven dried for 2.5 minutes at $100^{\circ} \mathrm{C}$ with subsequent curing for 4 minutes at $150^{\circ} \mathrm{C}$. The cured fabrics were rinsed in warm water to remove any finish residue and then air dried for further tests.

Untreated and DMDHEU treated cotton fabrics were repeatedly laundered, up to 10 cycles, in a Wascator FOM 71 MP washing machine using the 5A wash cycle programme. The machine complies with British Standards for domestic washing and drying testing procedures, BS EN ISO 6330:2001 + A1:2009. The washing was performed with $12.5 \mathrm{~g}$ of ECE non phosphate detergent in the presence and absence of 30 g sodium perborate and $4 \mathrm{~g}$ of TAED per wash.

\subsection{Crease Recovery Angle (CRA) Analysis}

The crease recovery of the fabrics was determined using the British Standard test method, BS EN 22313:1992 [32], with at least ten replicates performed in both and the mean for both warp and weft (W+F) reported.

\subsection{Kawabata System Evaluation for Fabrics (KES-F) Analysis}

The samples, $20 \mathrm{~cm} \times 20 \mathrm{~cm}$, were conditioned at $65 \%$ R.H. and $20^{\circ} \mathrm{C}$ for 24 hrs prior to testing. In this work only the tensile, shear, bending and compressional properties were analysed. The results presented were the average of three measurements taken along the warp and weft directions of the tested fabrics.

\section{Results and Discussion}

Examination of the CRA performance of the cotton fabrics treated with DMDHEU easy care finish indicates the CRA performance increased with an increase in application of DMDHEU, Figure 1. When the DMDHEU treated cotton fabric was laundered both with/without perborate there were marginal decreases in the CRA 


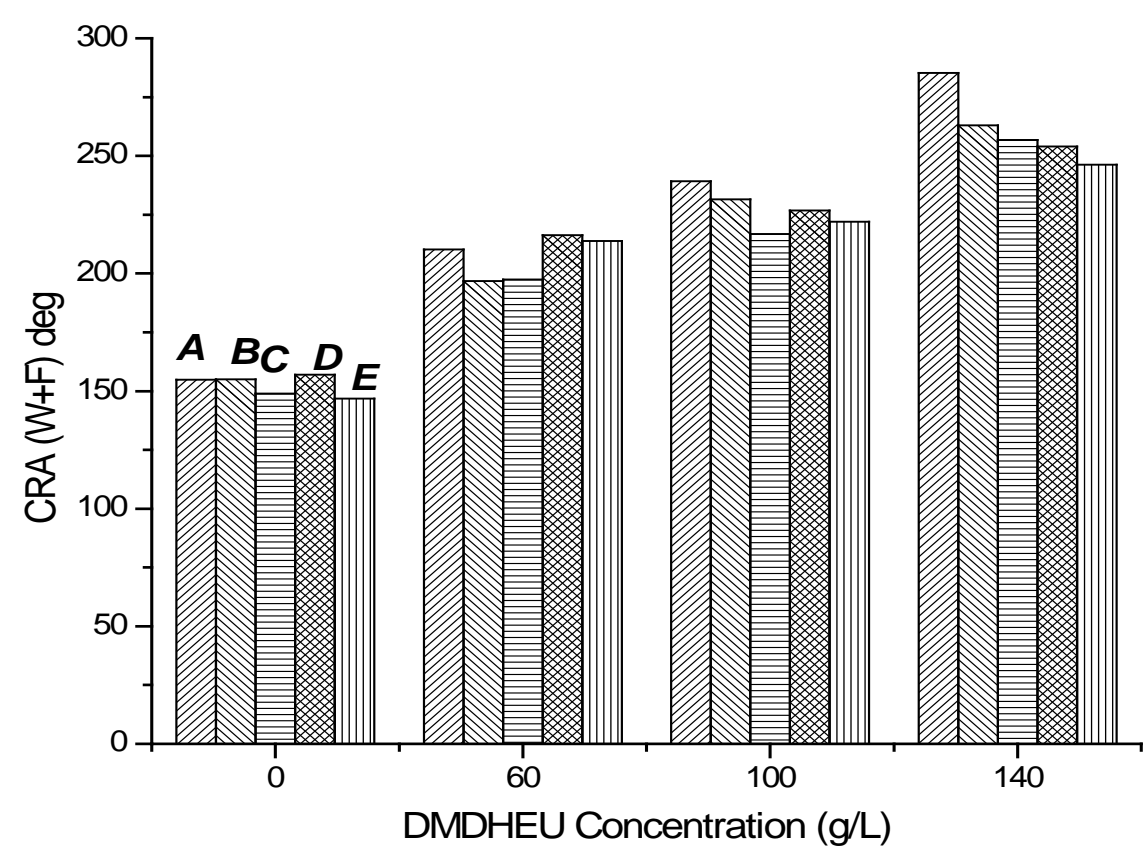

Figure 1. Effect of repeated washes, A-unwashed, B-one wash with perborate, C-ten washes with peborate, $\mathrm{D}$ - one wash without perborate, $\mathrm{E}$ - ten washes without perborate on the CRA performances. $(W+F)=$ warp + weft.

performance in the concentration range of 60 - $100 \mathrm{~g} / \mathrm{L}$ DMDHEU, but the decrease did not reach the level of the control cotton fabric (0 g/L DMDHEU). This observation agrees with the previously reported information that the DMDHEU is durable even after extended laundering [21]. While the decrease in CRA performance with the number of washes was relatively small in the $0-100 \mathrm{~g} / \mathrm{L}$ range, the decrease was more obvious at the 140 g/L DMDHEU application level, Figure 1. The nature of this phenomenon was discussed in detail in a previous study where the type of cellulosic crosslink introduced at varying levels of DMDHEU treatment was investigated.

Figure 2 presents the effect of extended washing on the extensibility (EMT) of the untreated and DMDHEU treated cotton fabric, as measured by the KES-F system. Treatment of the cotton fabric with increasing concentration $(60-100 \mathrm{~g} / \mathrm{L})$ DMDHEU produced an increase in the fabric extensibility. In contrast application of DMDHEU at $140 \mathrm{~g} / \mathrm{L}$ decreased the fabric extensibility below that of the untreated cotton. Fabric extensibility depends on the flexibility of the cellulose chain molecules to move. Application of DMDHEU crosslinks the cellulose chain molecules and thus restricts the mobility of the chains, while the aqueous padding of the fabric results in fabric relaxation and increased the fabric extensibility at $60-100 \mathrm{~g} / \mathrm{L}$ levels. At $140 \mathrm{~g} / \mathrm{L}$ DMDHEU the fabric relaxation effect cannot overcome the crosslinking effect, thus a measurable decrease in extensibility was observed. Subsequent Wascator washing relaxes the fabric, breaks bonds and increased EMT. Perborate washing caused greater oxidative damage and hence reduced EMT marginally less relative to the non-perborate washing.

The effect of repeated laundering on untreated fabric was to increase the fabric thickness and compressibility, Figure 3 and Figure 4. This increase was probably due to the fibrillation of the fibres and the formation of hairier and bulkier fabrics and stress relaxation of the fabric during washing. The effect of initial washing with perborate on the thickness of the fabrics treated with DMDHEU concentration was to reduce the fabric thickness $\mathrm{T}_{\mathrm{m}}$ and $\mathrm{T}_{\mathrm{o}}$, Figure 3 and Figure 4. This reduction in fabric thickness with the perborate wash treatment was probably due to its oxidative degradative effect preferentially removing embrittled surface fibres. Subsequently further fibres are able to become disengaged with the yarn structure, create a surface layer of protruding fibres and fabric thickness increased.

The effect of increasing DMDHEU application level was overall to increase the fabric rigidity above that of the untreated fabric, Figure 5. However with the 60 - $100 \mathrm{~g} / \mathrm{L}$ applications the bending rigidity actually decreased due to the fabric relaxation effect outweighing the crosslinking effect of the formaldehyde-based 


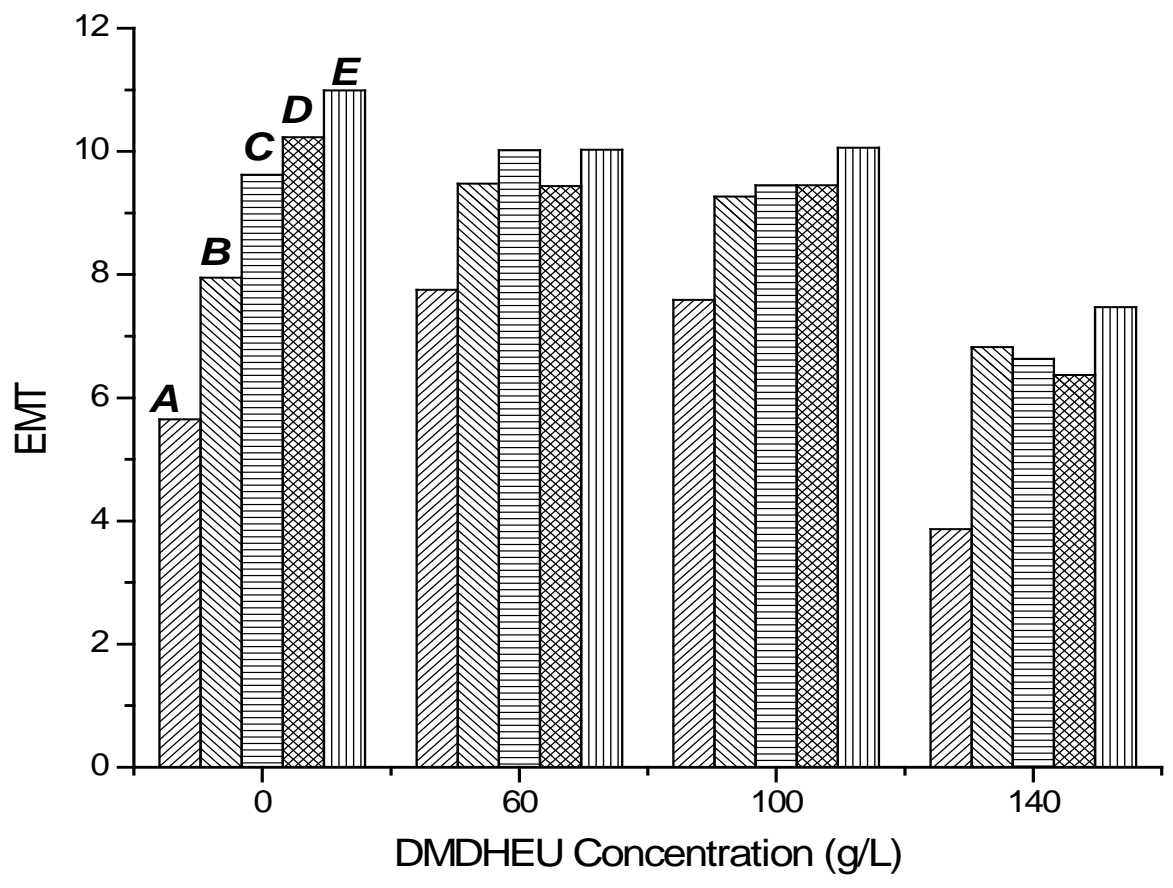

Figure 2. Effect of repeated washes, $A$ - unwashed, $B$-one wash with perborate, $C$ - ten washes with peborate, $D$-one wash without perborate, $E$ - ten washes without perborate on the extension.

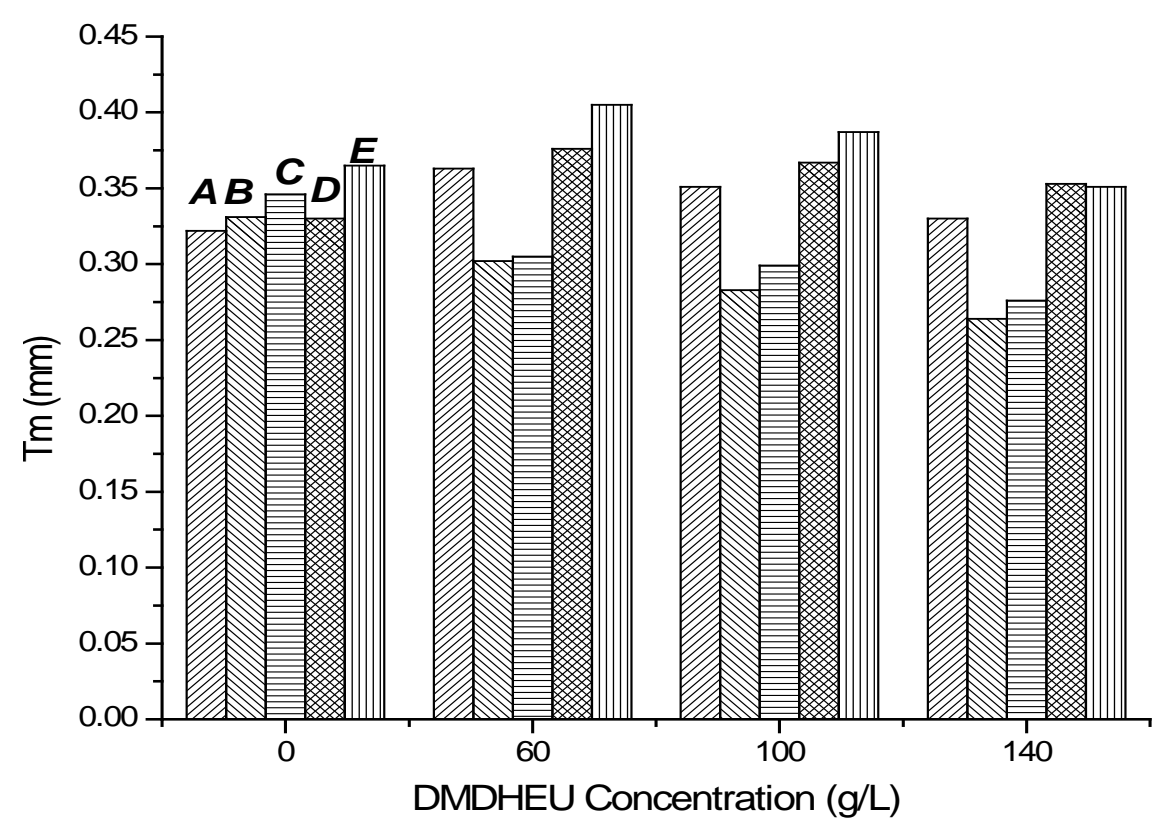

Figure 3. Effect of repeated washes, $A$-unwashed, $B$-one wash with perborate, $C$ - ten washes with peborate, $D$-one wash without perborate, $E$-ten washes without perborate on the thickness $\left(\mathrm{T}_{\mathrm{m}}\right)$ for cotton fabric.

crosslinker. Application of DMDHEU at the $140 \mathrm{~g} / \mathrm{L}$ level increased the bending rigidity above the untreated cotton value due to the crosslinking. In general subsequent laundering relaxed the fabric, broke internal bonds and decreased the bending rigidity. Little difference between the perborate wash and non-perborate washings was observed. 


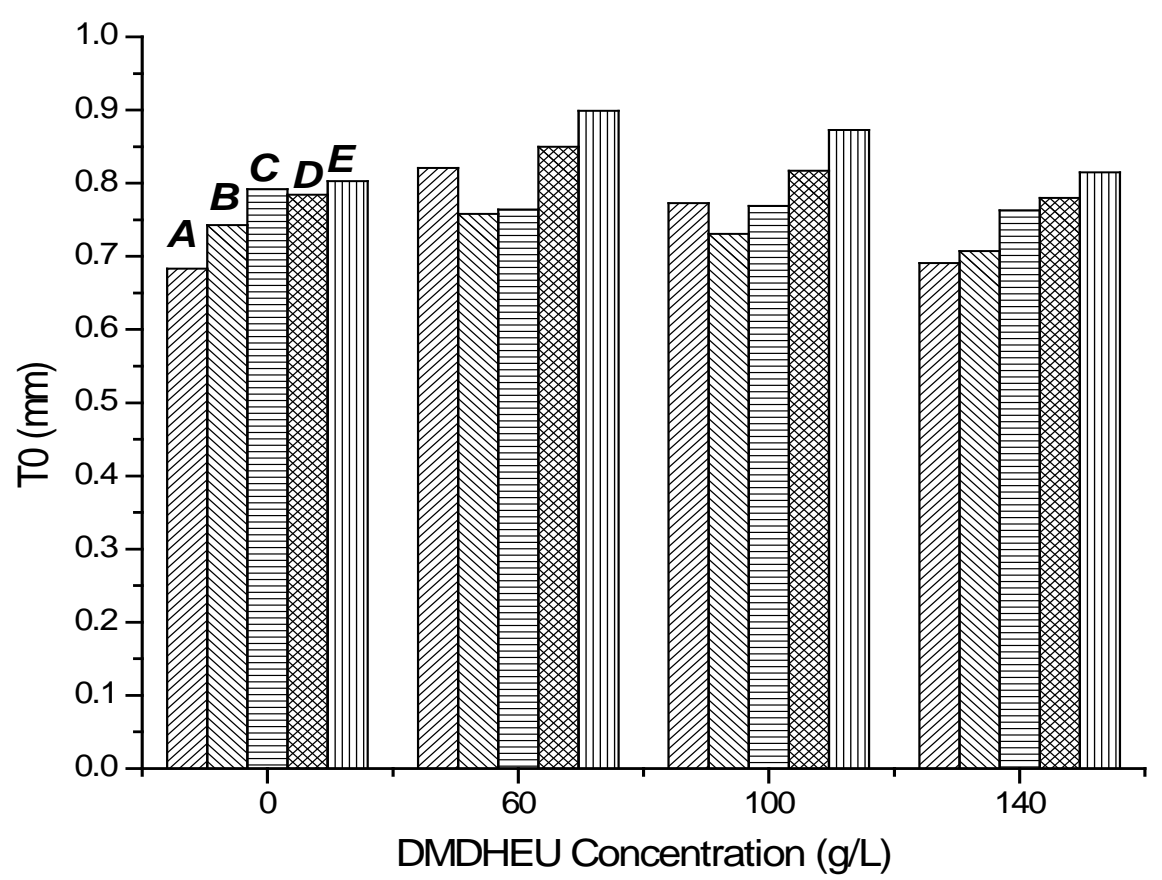

Figure 4. Effect of repeated washes, $A$-unwashed, $B$-one wash with perborate, $C$ - ten washes with peborate, $D$-one wash without perborate, $E$-ten washes without perborate, on the thickness $\left(\mathrm{T}_{0}\right)$.

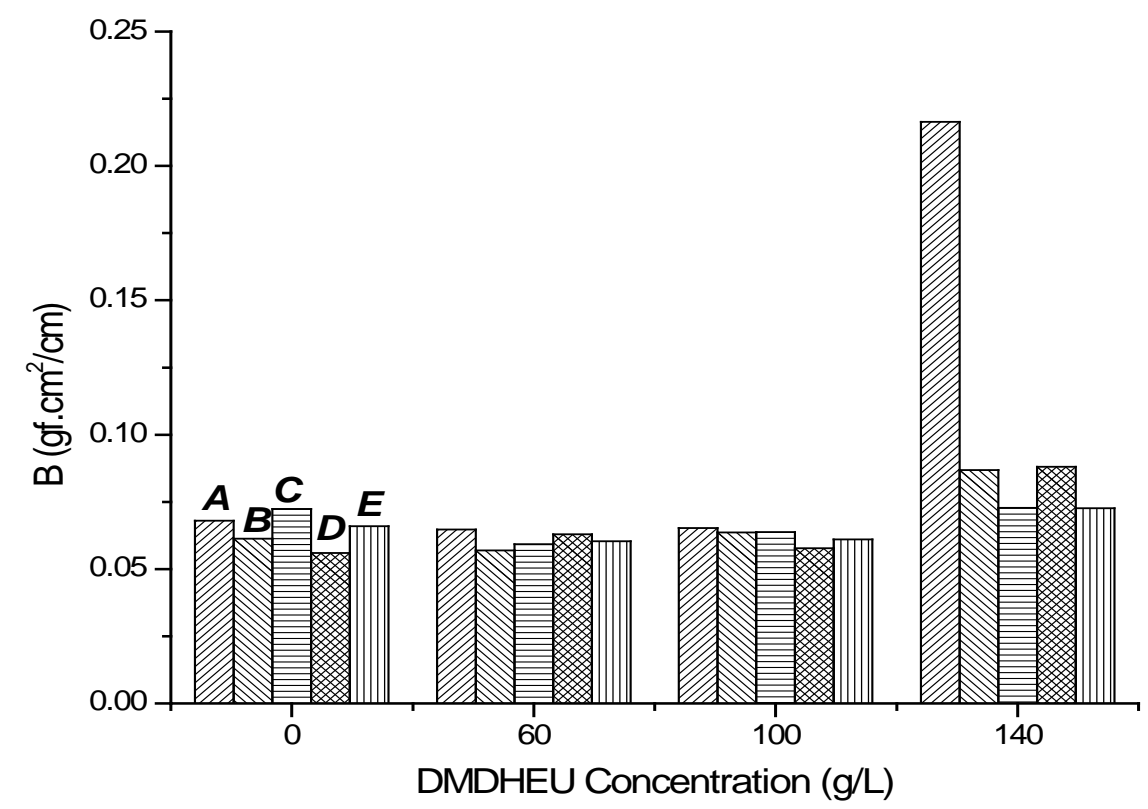

Figure 5. Effect of repeated washes, $A$ - unwashed, $B$ - one wash with perborate, $C$ - ten washes with peborate, $D$-one wash without perborate, $E$ - ten washes without perborate on the bending rigidity.

Figure 6 illustrates the effect of increasing DMDHEU treatment levels of cotton fabric and extended washing on the shear stiffness $(G)$ of the cotton fabric as measured by the KES-F system. Application of DMDHEU at $140 \mathrm{~g} / \mathrm{L}$ increased $\mathrm{G}$ due to crosslinking of the cellulose chain molecules within the fibre/yarn. Below this level the effect of aqueous padding relaxing the fabric predominated and decreased G. At 60 - $100 \mathrm{~g} / \mathrm{L}$ the crosslinking was counteracted by this relaxation. Subsequent Wascator washing relaxed the fabric, broke bonds and de- 
creased $\mathrm{G}$ for the $140 \mathrm{~g} / \mathrm{L}$ application and untreated cotton fabrics. For other application levels washing increased $\mathrm{G}$ and again little difference between perborate wash and non-perborate washing was observed.

Figure 7 presents the effect of DMDHEU concentration and extended Wascator washing on the shear hysteresis (2HG5) of the cotton fabric as measured by the KES-F system. Application of DMDHEU at $140 \mathrm{~g} / \mathrm{L}$ increased 2HG5 due to crosslinking of cellulose chains in the fibre. Below this level aqueous padding relaxed the fabric and decreased 2HG5. At 60 - $100 \mathrm{~g} / \mathrm{l}$ the crosslinking/embrittling effect was counteracted by this relaxation. Subsequent Wascator washing relaxed the fabric, breaks bonds and decreased 2HG5 for the $140 \mathrm{~g} / \mathrm{L}$ application and untreated fabric. For the other fabric treatments washing increased 2HG5 probably due to fibre surface modification increasing inter-fibre frictional interactions. Little difference between perborate wash and nonperborate washing was observed.

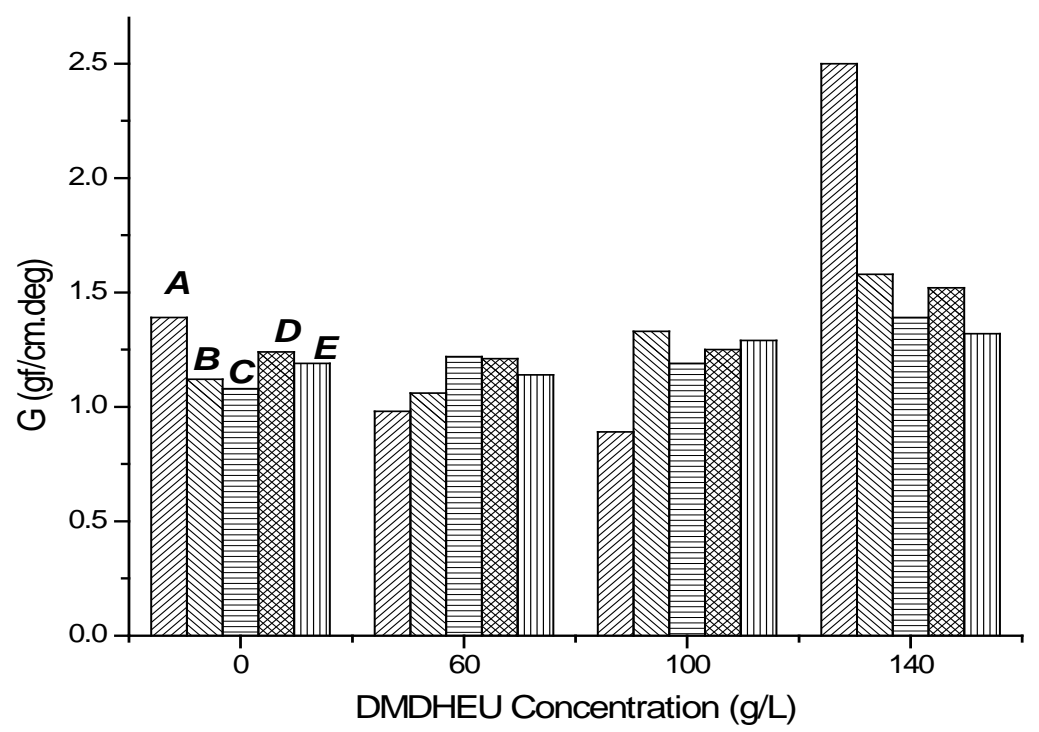

Figure 6. Effect of repeated washes, $A$ - unwashed, $B$-one wash with perborate, $C$-ten washes with peborate, $D$-one wash without perborate, $E$-ten washes without perborate on the shear rigidity.

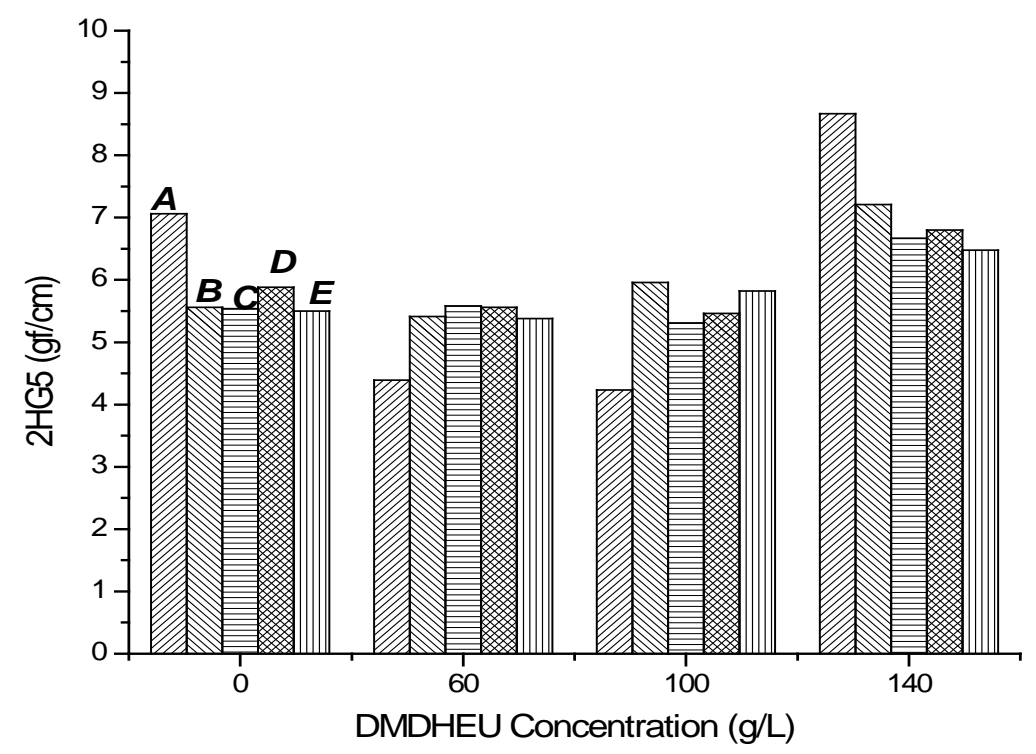

Figure 7. Effect of repeated washes, $A$ - unwashed, $B$ - one wash with perborate, $C$-ten washes with peborate, $D$-one wash without perborate, $E$-ten washes without perborate on the shear hysteresis at $5^{\circ}$ shear angle. 
Re-examination of the effect of repeated Wascator washing on the CRA performance, Figure 1, bending properties, Figure 5 and Figure 6 and shear properties Figure 7 indicated that the 140 g/L DMDHEU treated cotton has the relatively largest decrease in CRA performance, bending and shear rigidity properties when compared to 60 - $100 \mathrm{~g} / \mathrm{L}$ DMDHEU after repeated washing. Previous research has demonstrated that crosslinking of cotton fabrics with DMDHEU concentrations at lower than $140 \mathrm{~g} / \mathrm{L}$ favours tri- and tetra-functional crosslinks and the crosslinks are stable to extended laundering. However DMDHEU application at $140 \mathrm{~g} / \mathrm{L}$ is dominated by unstable bi-functional crosslinks [21]. Hence the measurable decrease in CRA performance, bending and shear properties of the cotton $140 \mathrm{~g} / \mathrm{L}$ DMDHEU treated, washed cotton fabric may be explained by the bi-functional crosslinks which are unstable to repeated Wascator washing and are prevalent at this higher application levels. Therefore the optimal application levels of DMDHEU easy care finish in cotton fabrics is anticipated to be in 60 $100 \mathrm{~g} / \mathrm{L}$.

\section{Conclusion}

Cotton fabrics were treated with DMDHEU at increasing concentration and the effect of extended laundering on the cotton fabric treated with DMDHEU easy care finish was investigated. The presence and durability of the easy care finish on the cotton fabric was monitored using the CRA performance. The CRA performance test results indicated that DMDHEU treatment at $(0-100 \mathrm{~g} / \mathrm{L})$ was stable to extended laundering conditions, however the $140 \mathrm{~g} / \mathrm{L}$ treatment was significantly affected by the extended laundering conditions and can be explained by the nature of crosslinking between cellulose polymer and DMDHEU at varying concentrations. The KES-F results indicated that the handle properties of the DMDHEU treated cotton fabrics were affected by both the level of application of the DMDHEU easy care finish and the stress relaxation of the fabrics in aqueous conditions. It was evident that the presence of perborate in the wash formulation had relatively little effect on the fabric handle properties above that observed with laundering with the non-perborate formulation.

\section{References}

[1] Grant, J.N., Orr, R.S., Tsoi, R.H. and Weiss, L.C. (1966) Strain-Recovery Properties of Wash-Wear-Treated Cotton Fabrics. Textile Research Journal, 36, 642-650. http://dx.doi.org/10.1177/004051756603600709

[2] Gilbert, S.M. and Smith, B.F. (1970) Degradation Study of Some Formaldehyde-Modified, Celluloses. Textile Research Journal, 40, 720-727. http://dx.doi.org/10.1177/004051757004000808

[3] Hassenboflfr, C.B.J.R., Harper, R.J. and Grant, J.N. (1971) Tensile, Shear, and Recovery Properties of Cotton Fibers and Fabrics Treated to Impart Differences in Wet and Dry Wrinkle Recoveries. Textile Research Journal, 41, 219-225. http://dx.doi.org/10.1177/004051757104100306

[4] Murphy, A.L., Margavio, M.F. and Welch, C.M. (1971) All-Cotton Durable-Press Fabrics of High Strength from Slack-Mercerized, Partially Restretched Yarn: Evidence for the Separate Origins of Strength and Wrinkle-Resistance Effects in Conventional Cross-Linking Treatments for Cotton. Textile Research Journal, 41, 22-31. http://dx.doi.org/10.1177/004051757104100105

[5] Grant, J.N., Andrews, F.R. and Weiss, L.C. (1971) Physical Properties of Cotton Treated by Pad-Dry-Cure, Mild-Cure, Poly-Set, and Wet-Fix Processes. Textile Research Journal, 41, 44-51. http://dx.doi.org/10.1177/004051757104100108

[6] Raheel, M. and Lien, M.D. (1982) Modifying Wear Life of All-Cotton Fabrics: Part I: Liquid Ammonia Treatment and Durable Press Finish. Textile Research Journal, 52, 493-503. http://dx.doi.org/10.1177/004051758205200802

[7] Jones, B.W., Turner, J.D. and Luparello, D.O. (1980) Preparing and Finishing Durable-Press Cotton Fabrics1. Textile Research Journal, 50, 165-177. http://dx.doi.org/10.1177/004051758005000305

[8] Hashem, M., Ibrahim, N.A., El-Shafei, A., Refaie, R. and Hauser, P. (2009) An Eco-Friendly-Novel Approach for Attaining Wrinkle-Free/Soft-Hand Cotton Fabric. Carbohydrate Polymers, 78, 690-703. http://dx.doi.org/10.1016/j.carbpol.2009.06.004

[9] Ibrahim, N.A., Abo-Shosha, M.H., Fahmy, H.M., El-Sayed, Z.M. and Hebeish, A.A. (2008) Hybrids for Finishing Cotton Fabric with Durable Handle Performance. Journal of Materials Processing Technology, 200, 385-389. http://dx.doi.org/10.1016/j.jmatprotec.2007.09.021

[10] Yang, C.Q. (2001) FTIR Spectroscopy Study of Ester Crosslinking of Cotton Cellulose Catalyzed by Sodium Hypophosphite. Textile Research Journal, 71, 201-206. http://dx.doi.org/10.1177/004051750107100303

[11] Yang, C.Q. (1991) FT-IR Spectroscopy Study of the Ester Crosslinking Mechanism of Cotton Cellulose. Textile Research Journal, 61, 433-440. http://dx.doi.org/10.1177/004051759106100801

[12] Yang, C.Q. (1991) Characterizing Ester Crosslinkages in Cotton Cellulose with FT-IR Photoacoustic Spectroscopy 1. 
Textile Research Journal, 61, 298-305. http://dx.doi.org/10.1177/004051759106100509

[13] Yang, C.Q. and Andrews, B.A.K. (1991) Infrared Spectroscopic Studies of the Nonformaldehyde Durable Press Finishing of Cotton Fabrics by Use of Polycarboxylic Acids. Journal of Applied Polymer Science, 43, 1609-1616. http://dx.doi.org/10.1002/app.1991.070430904

[14] Yang, C.Q., Chen, D., Guan, J. and He, Q. (2010) Cross-Linking Cotton Cellulose by the Combination of Maleic Acid and Sodium Hypophosphite. 1. Fabric Wrinkle Resistance. Industrial \& Engineering Chemistry Research, 49, 83258332. http://dx.doi.org/10.1021/ie1007294

[15] Yang, C.Q. and Dengjin, W. (2000) Evaluating Ester Crosslinking of Cotton Fabric by a Polycarboxylic Acid Using Acid-Base Titration. Textile Research Journal, 70, 615-620. http://dx.doi.org/10.1177/004051750007000709

[16] Yang, C.Q., Hu, C. and Lickfield, G.C. (2003) Crosslinking Cotton with Poly (Itaconic Acid) and in Situ Polymerization of Itaconic Acid: Fabric Mechanical Strength Retention. Journal of Applied Polymer Science, 87, 2023-2030. http://dx.doi.org/10.1002/app.12043

[17] Yang, C.Q., Lan, X., Shiqi, L. and Yanqiu, J. (1998) Nonformaldehyde Durable Press Finishing of Cotton Fabrics by Combining Citric Acid with Polymers of Maleic Acid. Textile Research Journal, 68, 457-464. http://dx.doi.org/10.1177/004051759806800611

[18] Yun, L. and Yang, C.Q. (1999) Fabric Yellowing Caused by Citric Acid as a Crosslinking Agent for Cotton. Textile Research Journal, 69, 685-690. http://dx.doi.org/10.1177/004051759906900909

[19] Weilin, X. and Shyr, T.-W. (2000) Durable Press Finishing of Cotton Fabrics by Polycarboxylic Acids After Graft Copolymerization with Hydroxyethyl Methacrylate. Textile Research Journal, 70, 8-10. http://dx.doi.org/10.1177/004051750007000102

[20] Xu, W. and Shyr, T. (2001) Applying a Nonformaldehyde Crosslinking Agent to Improve the Washing Durability of Fabric Water Repellency. Textile Research Journal, 71, 751-754. http://dx.doi.org/10.1177/004051750107100901

[21] Haule, L.V., Rigout, M., Carr, C.M. and Jones, C.C. (2012) Surface and Bulk Chemical Analysis of the Durability of an Easy Care Finish on Cotton. Cellulose, 19, 1023-1030. http://dx.doi.org/10.1007/s10570-012-9672-x

[22] Rijavec, T., Jevsnik, S., Soljacic, I., Tomljenovic, A., Visic, K. and Pusic, T. (2015) Physical and Chemical Effects of Washing and Wet Cleaning on Durable Press Finished Cotton Fabrics. Textile Research Journal, 85, 632-645. http://dx.doi.org/10.1177/0040517514547212

[23] Shenai, V.A. (1989) Fundamental Concepts of Fabric Hand. Part 1. Textile Dyer and Printer, 22, 19-26.

[24] Shenai, V.A. (1989) Fundamental Concepts of Fabric Hand. Part 2. Textile Dyer and Printer, 22, 15-22.

[25] Fritz, A. (1972) New Way to Measure Fabric Hand. Textile Asia, 23, 69-72.

[26] Carr, C.M. (1988) Investigation of the Effect of Water Repellent Finishes on the Mechanical Properties of Textiles Using the Kawabata Evaluation System for Fabrics. Journal of Industrial Textiles, 18, 106-113. http://dx.doi.org/10.1177/152808378801800205

[27] Roh, E.K., Oh, K.W. and Kim, S.H. (2014) Effect of Raising Cycles on Mechanical, Comfort, and Hand Properties of Artificial Suede. Textile Research Journal, 84, 1995-2005. http://dx.doi.org/10.1177/0040517514528561

[28] Bertaux, E., Lewandowski, M. and Derler, S. (2007) Relationship between Friction and Tactile Properties for Woven and Knitted Fabrics. Textile Research Journal, 77, 387-396. http://dx.doi.org/10.1177/0040517507074165

[29] Park, S., Yun, C., Kim, J. and Park, C.H. (2013) The Effects of the Fabric Properties on Fabric Movement and the Prediction of the Fabric Movements in a Front-Loading Washer. Textile Research Journal, 83, 1201-1212. http://dx.doi.org/10.1177/0040517512468810

[30] Parfitt, M., Vickerman, J.C., Mitchell, R., Carr, C.M., Ince, N. and Knight, P. (2003) Surface Analysis of Softened Paper by Time-of-Flight Secondary Ion Mass Spectrometry (ToF-SIMS) and the Kawabata Evaluation System. Journal of Materials Science, 38, 2171-2177. http://dx.doi.org/10.1023/A:1023728114543

[31] Lam, Y.L., Kan, C.W., Yuen, C.W. and Au, C.H. (2011) Low Stress Mechanical Properties of Plasma-treated Cotton Fabric Subjected to Titanium Dioxide Coating. Textile Research Journal, 81, 1008-1013. http://dx.doi.org/10.1177/0040517510396001

[32] British Standards Online (1992) Textile Fabrics. Determination of the Recovery from Creasing of a Horizontally Folded Specimen by Measuring the Angle of Recovery: BS EN 22313:1992, ISO 2313:1972. 